licence in the same group of patients until being linked to increased mortality and withdrawn. ${ }^{10}$ Should we not learn from history? And should we not use this opportunity to discuss the ethical aspects of advocating new and unproved indications for drugs in review articles as well?

Rogaland Central Hospital,

E SØREIDE

4011 Stavanger,

Norway

PA STEEN

Ullevål Hospital,

0407 Oslo,

1 Parke TJ, Stevens JE, Rice ASC, Greenaway CL, Bray RJ,

Parke TJ, Stevens JE, Rice ASC, Greenaway CL, Bray RJ,
Smith PJ, et al. Metabolic acidosis and fatal myocardial failure Smith PJ, et al. Metabolic acidosis and fatal myocardial failure
after propofol infusion in children: five case reports. $B M 7$ after propofol infusion in children:

2 Matthews AJ. Sedation, muscle relaxation, and analgesia in PICU. Care of the Critically Ill 1991;8:34.

3 Brockmeier V, Steen PA. The use of propofol in Norwegian hospitals. Tidsskr Nor Laegeforen 1992;112:2663-5.

4 Imray JmcG, Hay A. Withdrawal syndrome after propofol Anaesthesia 1991;46:704.

5 Bivirkningsnaevnet. Diprivan (propofol) bivirkninger. Ugeskr Laeger 1990;152:1176.

6 Trotter C, Serpell MG. Neurological sequelae in children after propofol infusion. Anaesthesia 1992;47:340-2.

7 Field L, James I. Respiratory support. Current Paediatrics 1992;2:26-40.

8 Saint-Maurice C, Hamaza J. Sedation techniques in paediatric anaesthesia. Current Opinion in Anaesthesiology 1992;5:392-7. anaesthesia. Current Opinion in Anaesthesiology 1992;5:392-7.
Rodgers EM. Diprivan intensive care sedation in children. Br $\mathcal{F}$ Anaesth 1991;67:505.

10 Ledingham IMcA, Watt I. Influence of sedation on mortality in critically ill multiple trauma patients. Lancet 1983;i:1270.

\section{Audit and research}

EDITOR,--It is unfortunate that confusion persists about the important distinction between research and audit.' Research aims to extend scientific knowledge. Clinical research examines what difference a particular clinical intervention will make in which patients. In other words, it tests the links between the processes and the outcomes of care and generates knowledge that is transferable-the results of research must be valid as facts that apply in every clinical practice.

Audit, however, aims to extend practitioners knowledge about their own practice. Audit examines whether the right intervention is being made in the appropriate patients with the expected success. Thus audit tests process and outcome independently, in the knowledge that the link has been established. Audit does not continually reexamine whether or not a particular intervention is efficacious. Instead it examines how effectively an intervention of proven efficacy is applied.

Because research must establish facts that stand in all similar circumstances, it treats the study population as sample. Thus the numbers of patients are crucial for statistical analysis of expected variation between one sample and the next.

Audit reveals facts (results) that apply only to the patients examined in the project (even though the lessons learned may be applied to other patients in the practice). Because analysis does not treat an audit study population as a sample the number of patients involved is not statistically importantaudit can be done on one patient alone. (This may be qualified-the number of patients audited should broadly represent the clinical practice so that, were a hundred cases seen a week, more would be audited than if one were seen a year. But the audit of that one would be valid. Also, a standard that is expressed as a proportion can only be audited on sufficient patients to allow statistically valid estimation of the proportion achieved within the practice.)

The use of scientific (research) methods to develop knowledge about disease and the efficacy of different clinical interventions has transformed health care over the past 100 years. The use of scientific (audit) methods to ensure effective practice through widespread application of that burgeoning knowledge could have an effect that is equally profound. The opportunity should not be lost because of failure to understand the differences between the principles and methods of each activity.

ADRIAN BULI

Eastbourne Health Authority,

Eastbourne,

East Sussex BN21 2BH

1 Smith R. Audit and research. BMf 1992;305:905-6. (17 October.)

\section{Italian NHS}

EnrtoR,-We read William Ward's news item from Italy with surprise.' Ward must be either uninformed, or a supporter of those who are trying to disqualify and possibly disband the Italian NHS.

Leaving aside its malevolent tone-with its reference to "Soviet style commissions" when Ward writes of the Unite Sanitaria Locales and its description of the Italian health care reform as "infamous"-the piece is full of inaccuracies: absurd estimates of the health expenditure of local governments, the alleged frequency of medical consultation of the population, and hospital porters threatening senior consultants. It is astonishing that a journal like the $B M \mathcal{-}$-known to have had a fundamental role in the analysis and defence of the British NHS with properly documented contributions-can accept such gossip as the sole contribution to knowledge of another health service.

Reliable, easily accessible information on what is at stake is widely available, even to a freelance journalist writing from Rome. For a sober outlook on the Italian NHS readers may wish to refer to a commentary to be published shortly.?

EMANUEL A TERZIAN GIANNI TOGNONI

Laboratory of Clinical Pharmacology,

Istituto Ricerche Farmacologiche "Mario Negri,"

20157 Milan,

Italy

1 Ward W. Italian medical system faces demolition. BMF 1992 305:849. (10 October.)

Garattini S. National health service intact but charges rise. Lancet (in press).

\section{Junior doctors' hours}

EDITOR,-C J K Bulstrode and colleagues propose a plan for reducing junior doctors' hours in which two of the solutions are reducing inappropriate duties and reducing work after midnight.' Unfortunately, neither approach is as simple as the authors seem to suggest, and no attempt is made to quantify the impact such measures might have.

Reducing inappropriate activities requires identification of tasks that could be done by someone else. For example, it may be more appropriate for some tasks undertaken by house officers, such as obtaining consent for surgery, to be undertaken by consultants in preadmission clinics. Agreement must then be sought with those who it is hoped will take over the task. For example, the reference to training nurses to administer intravenous drugs ignores the complexity of the relationship between doctors and nurses and the unwillingness of many nurses to accept delegation of tasks without a transfer of the associated decision making. ${ }^{2}$

Reducing work done after midnight is equally complex. Identification of those tasks that can be postponed safely entails balancing any risks of delay with those of being managed by a tired and often unsupervised junior doctor.

It is disappointing when authors fail to draw on scientific research to shape policy. Managers often complain that health services research does not address contemporary policy issues and thus fails to help resolve management dilemmas. While such complaints are often well founded, it is just as frustrating for researchers to see scientifically based evidence ignored in debates on policy. In this instance such evidence does exist. ${ }^{+9}$

MARTIN MCKEE NICK BLACK

Department of Public Health and Policy,

Health Services Research Unit,

London School of Hygiene and Tropical Medicine, London WC1E 7HT

1 Bulstrode CJK, Gray AJM, Anderson M, Hawke CI. New deal for doctors' hours: how to achieve it. BMf 1992;305:1203-5. (14 November.)

2 McKee M, Lessof L. Nurse and doctor: whose task is it anyway? In: Robinson J, ed. Policy issues in nursing. Buckingham: Open University Press, 1992:60-7.

3 McKee CM, Black N. Does the current use of junior doctors in the United Kingdom affect the quality of medical care? Soc Sci Med 1992;34:549-58.

4 Dowie R. Patterns of medical staffing: overview. London: HMSO, 1991

5 Turnbull NB, Miles NA, Gallen IW. Junior doctors' on call activities: differences in workload and work patterns among grades. BMF 1990;301:1191.

6 McKee CM, Ginzler M, Priest P, Black NA. How can the work of junior paediatricians be reduced? Arch Dis Child 1991;65: $1085-9$

7 McKee CM, Ginzler M, Priest P, Black N. Can out of hours work by junior doctors in obstetrics be reduced? Br $\mathcal{f}$ Obstet Gynaecol 1992;99:197-202.

8 McKee CM, Ginzler M, Priest P, Black N. The appropriateness of tasks performed by pre-registration house officers. Med Educ 1992;26:51-7.

9 McKee M, Ginzler M, Priest P, Black N. Which general surgicil operations must be done at night? Ann $R$ Coll Surg Engl 1991;73:295-302.

Editor,- The article by $\mathrm{C} \mathrm{J} \mathrm{K} \mathrm{Bulstrode} \mathrm{and}$ others' and the letters by C J McCullough ${ }^{2}$ and B N Summers and I S M Dwyer ${ }^{3}$ exemplify why many of us believe that the new deal cannot work without an increase in the number of senior house officers. For a full shift system a minimum of five doctors is needed, but this is "very unsatisfactory"'; for a partial shift four are needed, but at the cost of inadequate teaching time; and for an on call rota a minimum of five doctors are needed.

In many district general hospitals these numbers of doctors are not available. Most units are too busy to contemplate cross covering others, and an influx of senior house officers from the teaching centres has not occurred (and would cause problems in the teaching hospitals if it did). Furthermore, if this number of doctors was available I suspect that most would prefer to be on a 1 in 5 rota rather than any of the alternatives.

The Junior Doctors Committee was unfortunately duped by the Department of Health and the hierarchy of the BMA into accepting a plan that cannot work. Neither the department nor the BMA wants to see an increase in the number of doctors - the department for reasons of economy, and the BMA because it has always been acknowledged (though rarely stated openly) that the fewer doctors there are the more they can each demand in salary.

Sheffield S10 2BA

JEREMY WIGHT

1 Bulstrode CJK, Muir Gray AJ, Anderson M, Hawke CI. New deal for junior doctors' hours: how to achieve it. $B M 7$ 1992;305:1203-5. (14 November.)

2 McCullough CJ. Partial shifts. BMF 1992;305:1297. (21 November.)

3 Summers BN, Dwyer JSM. Partial shifts. BMF 1992;305:1297. (21 November.)

EDIToR,-I am uncertain whether this government is capable of reacting to a plea to change its position. Junior doctors must work shorter hours.' They must receive a good postgraduate medical education. They must have a goal to achieve-that is, adequate numbers of worthwhile senior posts to be filled at the end of their training. A service that already requires enormous expenditure on agency and other locum staff simply to survive with a 1 in 3 rota cannot expect to be adequately 
covered when existing staff are put on a 1 in 4 rota.

A substantial increase in the number of seniors (the latest call from the junior ranks) would help the situation. But those of us who are conscientiously trying to fulfil all the demands of clinical service to patients, education of our juniors, audit, and management know that this would irrevocably change for the worse the senior posts at which the juniors are aiming. It would endanger a service in which the apprenticeship method of transmitting skills and knowledge has thrived for so long.

Three steps should be taken. Firstly, there should be a temporary, substantial increase in junior staff to enable the reduction in hours to take place within the time span proposed. Much of this increase could later be phased out. Secondly, there should be an increase in the staff grade to achieve some of the proposed rotas. Thirdly, the number of consultants per 100000 population should be greatly increased towards the royal college's recommendations. This should be combined with discussions with consultants at the grassroots level (not the committee members who no longer spend time with patients) about how consultant practices could change.

Most of us are aware, and the government must be made aware, that the changes agreed with shortsighted leaders of junior doctors have created a situation that most junior doctors themselves do not relish-shifts, incomplete weekends, detachment from the consultant, and more difficulty in arranging their lives and educational needs. In the long run they may also realise that the gold carrot of the consultant grade being dangled in front of them to encourage their endeavours is simply a brass turnip.

Brook General Hospital

EL.LIS FIELD

London SE18 4LW

1 Bulstrode CJK, Muir Gray AJ, Anderson M, Hawke CI. New deal for junior doctors' hours: how to achieve it. $B M$ F 1992;305:1203-5. (14 November.)

\section{Specialist training}

EDIToR,-I am sorry to dismay R J Baigrie and M W R Reed,' but they have misunderstood some of the implications of the National Association of Health Authorities and Trusts' discussion paper ${ }^{2}$ and misinterpreted others.

NAHAT would like to see hospital doctors in Britain able to practise as fully independent professionals by their early 30 s; it accepts the several compelling arguments for moving "from a consultant led service to a consultant based one." This will require a considerable expansion of the present consultant grade and a concomitant reduction in the number of junior staff. It follows that between half and two thirds of future consultants will not have their present supporting junior staff.

If clinical standards are to be maintained, earlier appointment means that the reduced years of clinical experience while training must be offset by more intensive and targeted educational programmes. With fewer juniors sharing the service load and their individual contribution reduced because of their enhanced training programme, future consultants will have to bear a much greater proportion of the service load and provide the extra training. No wonder that Steve Kisely and Richard Morriss warn against doctors "sacrificing the long term quality of their careers for short term advantages" and correctly identify that "in addition to the responsibilities of existing consultants they would assume a much greater on call commitment, including, possibly, being resident in hospital at night until retirement." " Under NAHAT's proposals, however, the requirement for a consultant to be resident while on duty might apply to specialists but not necessarily to senior specialists.
By recognising the difference between senior and junior consultants in our proposal for a senior specialist grade NAHAT wished to ensure that those responsible for supervising training would have the correct experience and would themselves have received some training as educators. Appointment to this grade would therefore not be automatic, but all suitably qualified candidates could apply, thus maintaining a much more satisfactory career structure. Additionally, senior specialists would be recognised as having greater experience and skill and would be expected to deal with tertiary referrals. In employing them trusts could justifiably claim to be providing a higher quality service; this would ensure that medical skill and a high standard of medical practice would continue to be spread widely around the country as at present and would diminish the risk of a two tier system developing.

NAHAT would not tolerate any lowering of standards; it is committed to providing the highest quality of care for patients, which should be provided by fully trained specialists, practising to the same high standards as are expected of present day consultants.

\section{Chairman, Medical Manpower, Teaching}

G S SPATHIS

Association of Health Authorities and Trusts,

St Anthony's Hospital,

North Cheam,

1 Baigrie RJ, Reed MWR. Specialist training. BM7 1992;305:1021. (24 October.)

2 National Association of Health Authorities and Trusts. Medical manpower: training and hospital career structure. Birmingham NAHAT, 1992

3 Kisely S, Morriss R. Specialist training. BMF 1992;305:1021. (24 October.)

\section{Abortion in Poland}

EDrTor,-According to the map published in the news section recently, ${ }^{\prime}$ abortion is legally available in Poland. In fact, for a year now abortions have been totally banned here. Thanks to Catholic fundamentalists in Poland, nobody dares to perform the procedure. Hospitals have stopped performing abortions and doctors risk losing their licence to practise. Propaganda against contraception is increasing, sex education is banned, and contraceptives are becoming increasingly difficult to obtain.

ZBIGNIEW SZAWARSK

81-839 Sopot,

Poland

Abortion: how available is it for women around the world? $B M \mathcal{J}$ 1992;305:976. (24 October.)

\section{Health economics in the NHS}

EDITOR,- - Health economics has assumed a higher profile in NHS management over the past few years, but Ray Robinson and Bill New clearly show that expertise in this discipline is lacking among the staff of district health authorities. ${ }^{1}$ Furthermore, most health authorities apparently fail to appreciate the importance of taking economic advice when purchasing health services. I suspect, therefore, that most health authorities are also unaware of the existence of a national organisation whose function is to promote and facilitate the use of health economics in the NHS. I refer to the NHS Health Economics Group, founded in 1986.

The group has been successful in uniting a group of people who share the belief that economics has a central role in the rational distribution of scarce health care resources. We have found that many people working in the health service have an enthusiasm for health economics and wish to know more about such topical issues as the measurement and valuation of improvements in health and the relation between economics and the current health reforms. The group provides a forum through which NHS employees with an interest in health economics can maintain and develop their skills in methods of economic appraisal, exchange ideas and submit them to peer review, and establish links with professional health economists.

With the resources available to them district health authorities have a responsibility to secure the best possible health care services for the populations they serve. It seems self evident that economics should be an integral part of the decision making processes through which this purchasing role is fulfilled. In recognition of this some health authorities encourage their staff to acquire the necessary skills to be able to apply health economics techniques.' The NHS Health Economics Group supports this initiative.

NHS Health Economics Group M JENNINGS

University Department of Medicine and Pharmacology, Royal Hallamshire Hospital,

Sheffield S10 2JF

1 Robinson R, New B. Health economics and economists in the NHS. BMF 1992;305:1361. (28 November.)

\section{Interpreting fluorescein angiograms}

EDIToR,-R de Silva and C Santosh present a picture report of a case of swelling of the optic disc associated with buried drusen of the head of the optic nerve and state that late leakage of dye on fluorescein angiography is a recognised diagnostic pointer.' In fact, leakage argues against a diagnosis of disc drusen as a cause of disc swelling. Leakage of dye from the dilated prepapillary capillary plexus is an important feature of disc swelling due to raised intracranial pressure. In the presence of disc drusen the disc may become hyperfluorescent owing to uptake of dye during angiography but there is characteristically no abnormal leakage. ${ }^{2-5}$

I suspect that the authors have used the specific term "leakage" when they mean staining or perhaps hyperfluorescence in general. During fluorescein angiography dye diffuses out of the choriocapillaris and stains the sclera, disc margins, and lamina cribrosa. Late fluorescence of the disc-that is, fluorescence that persists after dye has mostly left the ocular circulation-is therefore a feature of all angiography. Leakage should be used only to imply escape of dye from vascular compartments or through tissue barriers that normally retain it-for example, the disc and retinal vasculature and the retinal pigment epithelium. Hyperfluorescence caused by leakage of dye from abnormal prepapillary capillaries in established papillo-oedema is characteristically intense and progressively extends beyond the margins of the disc during angiography. The hyperfluorescence associated with disc drusen retains a well defined margin.

This case illustrates the importance of taking care over terminology when interpreting fluorescein angiograms.

Eye Unit,

BARBARA HARNEY

Royal United Hospital,

Bath BA1 3NG

1 Minerva. $B M 7$ 1992;305:1374. (28 November.)

2 Cartlidge NEF, Ng RCY, Tilley PJB. Dilemma of the swollen optic disc: a fluorescein retinal angiography study. $\mathrm{Br} f$ Ophthalmol 1977;61:385-9.

3 Sanders MD, ffytche TJ. Fluorescein angiography in the diagnosis of drusen of the disc. Transactions of the Ophthalmological
naters nosis of drusen of the disc. Transactions of the
Society of the United Kingdom 1967;87:457-68.

4 Sanders MD, Sennhenn RH. Differential diagnosis of unilateral optic disc oedema. Transactions of the Ophthalmological Society of the United Kingdom 1980;100:123-31.

5 Schatz H. Fluorescein angiography: basic principles and interpretation. In: Ryan SJ, ed. Retina. C V Mosby, 1989 